\title{
Con el futuro que soñamos los neogranadinos: proposiciones de avance económico para una nueva realidad social (1778-1813)*
}

\author{
[Artículos]
}

\author{
Rodrigo Hernán Torrejano Vargas ${ }^{* *}$ \\ Henry Bocanegra Acosta***
}

Fecha de recepción: 4 de marzo de 2021

Fecha de aprobación: 18 de mayo de 2021

Citar como

Torrejano Vargas, R. H. y Bocanegra Acosta, H. (2021). Con el futuro que soñamos los neogranadinos: proposiciones de avance económico para una nueva realidad social (1778-1813). Via Inveniendi Et Iudicandi, 16(2).

https://doi.org/10.15332/19090528.6784

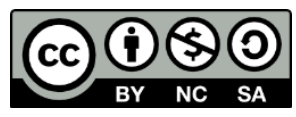

\footnotetext{
* Artículo en colaboración, producto de la investigación desarrollada por los autores, quienes contribuyeron con la recopilación y examen de la información, las elaboraciones y la síntesis teórica con sus grupos y proyectos de investigación institucionales: Derechos, movimientos sociales y políticas públicas, del Grupo de Investigaciones Socio Jurídicas (GISJ), del Centro de Investigaciones Socio Jurídicas de la Universidad Libre, sede principal; y Política pública, identidad y representaciones sociales de las profesiones en Colombia en el marco de la vida republicana, siglos XIX y XX, del Grupo Derecho Público y Sociedad, de la Corporación Universitaria Republicana, Bogotá D. C.

** Magíster en Historia por la Universidad Externado de Colombia. Licenciado en Ciencias Sociales por la Universidad Distrital Francisco José de Caldas. Docente e investigador de la Corporación Universitaria Republicana, grupo de investigación Derecho Público y Sociedad. Investigador asociado a Minciencias. Correo electrónico: rtorrejano@gmail.com; ORCID:

https://orcid.org/0000-0002-2672-9831

*** Doctor en Sociología Jurídica e Instituciones Políticas por la Universidad Externado de Colombia. Especialista y magíster en Administración Pública por la Escuela Superior de Administración Pública (ESAP). Magíster en Educación por la Universidad Antonio Nariño. Abogado de la Universidad Libre. Licenciado en Ciencias de la Educación, especialidad sociales. Docente investigador de la Universidad Libre, asociado al Grupo de Investigaciones Socio Jurídicas (GISJ); docente de la Corporación Universitaria Republicana. Investigador asociado a MinCiencias. Correo electrónico: henrybocanegra1992@yahoo.es; ORCID: https://orcid.org/0000-0001-7623-7483
}

Via Inveniendi Et Iudicandi

e-ISSN: 1909-0528 | DOI: https://doi.org/10.15332/19090528

Vol. 16 N.o 2 | julio-diciembre del 2021 


\section{Resumen}

El presente artículo, de corte historiográfico, identifica y explica los planteamientos de índole económico esbozados por destacados criollos ilustrados desde finales del siglo XVIII hasta comienzos de la segunda década del siglo XIX, con el propósito de emprender un conjunto de reformas estructurales que eliminaran los obstáculos que impedían el desarrollo económico y social del virreinato, y después, claramente, de la República de la Nueva Granada. Estudio realizado desde la perspectiva de la combinación del colectivismo metodológico, en el que las condiciones materiales y culturales son fundamentales para contextualizar y explicar los procesos históricos, y el individualismo metodológico, que nos advierte de la presencia y la injerencia de los episodios individuales en la confección de un proceso en el tiempo y el espacio, que nos permitieron establecer que todas las proposiciones presentadas en este breve periodo nacieron de la matriz del liberalismo ilustrado, toda vez que propusieron la liberación de los factores de producción (tierra, capital y mano de obra), la extinción de los monopolios y la abolición del tributo indígena.

Palabras clave: liberalismo, progreso económico, avance social, reforma estructural.

\section{The future we Neogranadines dream of: propositions for economic advancement for a new social reality (1778-1813)}

\section{Abstract}

This historiographical article identifies and explains the economic approaches outlined by prominent enlightened Creoles from the late 18th century to the early 19th century, with the purpose of undertaking a set of structural reforms that would eliminate the obstacles that prevented economic and social development of the viceroyalty, and later, clearly, of the Republic of New Granada. This study was carried out from the perspective of the combination of methodological collectivism, in which

Via Inveniendi Et Iudicandi

e-ISSN: 1909-0528 | DOI: https://doi.org/10.15332/19090528

Vol. 16 N.o 2 | julio-diciembre del 2021 
material and cultural conditions are fundamental to contextualize and explain historical processes, and methodological individualism, which warns us of the presence and interference of individual episodes in the making of a process in time and space. This allowed us to establish that all the propositions presented in this brief period were born from the matrix of enlightened liberalism, since they proposed the liberation of the factors of production (land, capital and hand of work), the extinction of monopolies and the abolition of the of the indigenous tribute.

Keywords: liberalism, economic progress, social advancement, structural reform.

\section{Introducción}

La presente indagación histórica versa sobre los planteamientos económicos formulados por un grupo de ilustrados criollos a las autoridades virreinales y monárquicas entre 1778, fecha de publicación del documento, La Provincia de Santa Marta y Riohacha del Virreinato de Santafé, del criollo Antonio de Narváez y la Torre, y 1813, año de la Declaración de independencia de la provincia de Tunja, con el expreso objetivo de proponer un programa básico de reformas económicas estructurales encaminadas a permitir y facilitar la gestación de iniciativas empresariales capaces de crear riqueza y estabilidad.

Dichos planteamientos económicos (hablaremos de ellos más adelante) deben entenderse en el marco de la implementación de las reformas borbónicas y su espíritu programático: la liberalización de la economía (Lynch, 1987), lo que es igual a decir: romper el cerco mercantilista en el que funcionó el comercio colonial desde el siglo XVI. No obstante, el estado beligerante en el que permaneció España con Inglaterra y Francia durante las últimas décadas del siglo contribuiría a que el espíritu de las reformas borbónicas no tuviera oportunidad de desplegarse con contundencia. 
Debemos recordar que las reformas borbónicas fueron un amplio paquete de proposiciones aplicado desde el reinado de Felipe V (1700-1746), el primer rey de la dinastía Borbón, quien con su equipo económico introdujo ciertas modificaciones al pesado sistema mercantil de comercio, destacándose el aumento del número de navíos mercantes para tratar de regularizar el tráfico con las colonias y la constitución de empresas privadas por acciones que se encargarían del intercambio en las regiones más periféricas del imperio y cercanas a las de las potencias rivales (Torrejano, 2010a). Ese fue el caso de la Compañía Guipuzcoana de Caracas (1728) (Martínez, 1994, p. 203).

Más adelante, el itinerario reformador continuó con el rey Carlos III (17591788), quien reforzó el principal axioma de la política económica de su predecesor: crecer económicamente "sobre las posibilidades inmediatas y de largo plazo de la economía colonial (Stanley y Stein, 1981, p. 87), profundizando el tono liberal de las reformas (Jaramillo, 1991), que adquiere forma con el Decreto y Real Instrucción del 16 de octubre de 1765, con el que desapareció el monopolio gaditano y se habilita un total de nueve puertos en España para el tráfico con América: Sevilla, Alicante, Gijón, Barcelona, Santander, La Coruña, Málaga y Cartagena, además de Cádiz, sin olvidar la introducción del principio de tributación ad valorem en reemplazo del palmeo, y el Reglamento y Aranceles para el comercio libre de España y las Indias de octubre de 1778, que consolida las medidas del reglamento de 1765, como lo muestra esta apreciación de Martínez (1994): "habilitación de varios puertos del litoral español y americano para comercio directo; consolidación del navío de registro suelto [...] sustitución de los derechos de palmeo y toneladas por [...] tributación advalorem" (p. 206). Dichos puertos ibéricos habilitados para el comercio transatlántico fueron: Palma de Mallorca, Los Alfaques, Almería y Santa Cruz de Tenerife. En el lado americano trece puertos menores: Puerto 
Rico, Santo Domingo, Monte Christi, Santiago de Cuba, Trinidad, Margarita, Campeche, Santo Tomás de Castilla, Omoa, Riohacha, Portobelo, Chagres y Santa Marta (Torrejano, 2010a).

Empero, todas estas reformas no colmaron totalmente las expectativas de desarrollo económico y bienestar social del selecto grupo de ilustrados neogranadinos. El malestar persistió, en el sentido de seguir pensando que las reformas eran medidas insuficientes, porque nada se decía de la estrategia para fomentar la economía interna; es decir, nada se escribió sobre los mecanismos y procedimientos para estimular el progreso de la agricultura, la ganadería, la minería y el comercio del virreinato y sus asimétricas regiones (Naranjo, Naranjo y Navas, 2018).

Este sentimiento de inconformismo nutrió la idea de elaborar y presentar pormenorizados informes económicos que partieran de un diagnóstico y concluyeran con la presentación de un plan de acción, digamos, un programa económico para el desarrollo. Estos programas se pensaron, al principio, desde la institucionalidad monárquica y la economía colonial, es decir, fueron planeados con una intención reformadora, pero con el paso de los acontecimientos que golpearon la estabilidad y la permanencia de la monarquía borbónica a principios del siglo XIX, terminaron convirtiéndose en programas que debía adoptar y poner en práctica las autoridades republicanas regionales y nacionales para tratar de superar la condición de periferia colonial secundaria atrasada y pobre (Llano, Rengifo y Rojas, 2018).

\section{Programas para el desarrollo económico}

Los programas en favor del desarrollo económico, diseñado por criollos ilustrados y pudientes a finales del periodo de dominio colonial, fueron la base de la política económica de los diferentes gobiernos republicanos de buena parte del siglo XIX, por lo menos hasta que los liberales radicales

Via Inveniendi Et Iudicandi

e-ISSN: 1909-0528 | DOI: https://doi.org/10.15332/19090528

Vol. 16 N.० 2 | julio-diciembre del 2021 
perdieron el poder en 1880. Así que, desde este punto de vista, la independencia nacional, si bien fue un acto de ruptura del dominio colonial, también trasluce un acto de continuidad frente a las iniciativas de desarrollo económico del periodo de las reformas borbónicas que, obviamente, tuvieron la oportunidad de aplicarse solo después de la Independencia.

Entre los programas escritos a finales del siglo XVIII y el albor del siglo XIX, con el objetivo de dinamizar la economía del virreinato de la Nueva Granada, son bastante bien conocidos los expuestos por don Antonio de Narváez y la Torre, criollo cartagenero, gobernador de Santa Marta, Riohacha, Panamá y Cartagena, firmante de la Declaración de Independencia del 11 de noviembre de 1811, escrito en 1778, en el escrito: Provincia de Santa Marta y Riohacha del Virreinato de Santafé 1778, y don José Ignacio de Pombo, criollo payanés, abogado y comerciante, cabeza visible del consulado de comercio de Cartagena, en el escrito: Memoria sobre el contrabando en el virreinato de Santafé, redactado en 1800 y 1804 .

Entre los programas concebidos durante las dos primeras décadas del siglo XIX, entre 1808 y 1813, sobresalieron los expuestos por los criollos Camilo Torres Tenorio, Antonio de Villavicencio, Ignacio de Herrera y Vergara, Frutos Joaquín Gutiérrez y Eloy Valenzuela, junto con lo consagrado en el acta de conformación de la Junta provincial de gobierno de Antioquia de 1810 y el Acta de Declaración de Independencia de la provincia de Tunja de 1813 .

Curiosa y paradójicamente, toda la inconformidad expresada por los criollos contra el mandato económico de la monarquía ibérica colonial, contrasta fuertemente con los datos positivos de comportamiento de la economía virreinal de finales del siglo XVIII. De acuerdo con Meisel (2010), este era su panorama: 
La buena situación también se veía en la producción agrícola. Los recaudos de los novenos reales, que eran la parte de los diezmos que iban para la Corona, reflejaban un aumento de dicha producción. Por ejemplo, entre 1761 y 180o, los ingresos de los novenos reales se duplicaron, de lo que se puede inferir que se debía estar duplicando también la producción agropecuaria. En esa época, la minería y la agricultura sumaban entre el 70 y el 80 por ciento del Producto Interno Bruto (PIB) de la Nueva Granada en esa época. El total de los ingresos fiscales creció entre 1760 y 1800 a una tasa anual promedio de 4,7 por ciento, que era bastante buena, e incluso superior al del aumento de la población. Esta última creció entre 1779 y 1800, a una tasa anual promedio del 1,7 por ciento. Por lo tanto, y como no había inflación, podemos hablar de un crecimiento en los ingresos fiscales en términos reales por encima del crecimiento demográfico. (p. 4)

Pero así como la economía mostraba un comportamiento vigoroso (Kalmanovitz, 2008), la carga fiscal igualmente creció a través del mismo lapso, por lo que el "crecimiento económico no se reflejó en mejoras sustanciales en la calidad de vida de los neogranadinos" (Meisel, 2010, p. 5) y motivó la generalización de un sostenido sentimiento de inconformismo que, a la postre, dejaría sus huellas en el levantamiento de los comuneros de 1781 y, por supuesto, en la presentación de todos estas propuestas de acción económica que le permitirían a la economía sostener su crecimiento y que las ganancias terminaran impactando de forma positiva el nivel de vida de los neogranadinos y la propia dinámica del sector productivo y comercial.

\section{Programas para el desarrollo economico escritos a finales del siglo XVIII: los casos de Antonio de Narváez y José Ignacio de Pombo}

En estricto orden cronológico, el primer programa que describiré es el que presentó a las autoridades coloniales el criollo Antonio de Narváez y la 
Torre (1733-1812) en 1778, con miras al repunte de la economía del Caribe. Él se concentró en la descripción del potencial agrícola de la zona, indicando que era apta para el cultivo de trigo, cacao, caña de azúcar, tabaco y algodón en grandes propiedades que podían surtir el mercado regional hasta la ciudad de Panamá.

En relación con el cultivo del trigo, Narváez consideró que daría lugar al desarrollo de una industria molinera que sustituiría la importación de harina y acabaría con la dependencia que tenían para su provisión de los mercaderes ingleses, dejando consigo inobjetables ventajas fiscales, según se lee en el siguiente texto:

Y solo este renglón (además de asegurar la subsistencia de la importante plaza de Cartagena, y de las demás de la Costa a que se conducen por mar, que fácilmente ocupan y embarazan en tiempo de guerra los corsarios enemigos) habría hecho entrar en esta provincia, y quedar en el Reyno más de 100.00o pesos anuales que la de Cartagena se consumen en harinas, y se han llevado por mucho tiempo los ingleses, y aún podría proveer de él, las ciudades de Portobello y Panamá, de donde han sacado igualmente. Con el mismo motivo somos muy considerables, que si hubiesen quedado en el Reyno hubieran aumentado notablemente sus fondos, y avivado su comercio con el giro interior y repetidas operaciones que la abundancia de dinero facilita. (Narváez, 2010, p. 26)

Frente al cultivo del algodón estimó que la producción de la materia prima debía acompañarse con el establecimiento de un centro de manufactura textil que reemplazaría los bienes industriales importados y permitiría la acumulación de cierta dosis de capital en la región. Observemos con más detalle este punto de vista:

Mi primer pensamiento en esto fue irles así aficionando, y preparando para otra fábricas de la más extensión, e importancia; porque a primera vista me parecía que, si en estos mismos parajes en que se coge el

Via Inveniendi Et Iudicandi

e-ISSN: 1909-0528 | DOI: https://doi.org/10.15332/19090528

Vol. 16 N.o 2 | julio-diciembre del 2021 
algodón se estableciesen, (trayéndose maestros y máquinas para ello) las fábricas de angarípolas, pañuelos, fulas y otras que se hacen de él, evitándose los costos y fletes de conducción de esta materia en basto a España, y reconducción acá después de manufacturados...podrían darse acá a mucho menos precios, y dejan mayor utilidad al Rey y al Vasallo. (Narváez, 2010, pp. 29-30)

En su opinión, todos estos cultivos comerciales tendrían éxito siempre y cuando el gobierno facilitara la importación de mano de obra esclava, en vista de que la fuerza de trabajo disponible distaba de poseer las condiciones y características que una producción metódica y disciplinada demandaba. Según él, los indígenas y mestizos de la región traían a cuesta el lastre de su natural inclinación a la pereza y la ociosidad como se anota a continuación:

Los indios pacificados y tributarios de la provincia: son poquísimos: su natural abandono y habituado a la ociosidad en que han nacido y criándose, les ha hecho contraer una especie de aversión invencible al trabajo. Los mulatos, zambos, negros libres, mestizos y demás castas de gentes comunes del país [...] participan mucho de este carácter, y aún el clima concurre a formarle, o fortificarle [...] porque siendo tan cálido disipa con el continuo sudor las fuerzas. (Narváez, 2010, p. 49)

En cambio, los negros esclavos tenían la fortaleza física y la robustez necesaria para laborar en condiciones naturales similares a las de su tierra de origen y una vez causado el desembolso inicial de cierta cantidad de dinero por su compra, el inversionista ahorraría costos de producción durante el funcionamiento del proyecto, preocupándose únicamente por su manutención y vestuario, "que es muy limitado y hacen los trabajos mucho menos costosos y por consiguiente mucho más útiles" (Narváez, 2010, p. 50). Para la compra de la mano de obra esclava negra se le ocurrió que la ayuda estatal era condición de primerísimo orden, por lo que sugirió 
que el gobierno facilitara una línea de crédito con plazo de 5 a 6 años para su pago, pues los potenciales empresarios interesados en el negocio carecían de liquidez para iniciarlo.

Por su parte, el criollo payanés José Ignacio de Pombo escribió en 1800 el Informe del Real Tribunal del Consulado de Cartagena de Indias al virrey del reino y, en 1804, la Memoria sobre el contrabando en el virreinato de Santafé. En ambos documentos propugna, en representación de los comerciantes matriculados en el Consulado, por la parcial liberalización del comercio como antídoto contra el contrabando y la protección de cierta franja de bienes como estímulo a los productores domésticos. Sería partidario de una liberalización diferenciada del comercio colonial. Esto significa que abogó por la disminución de la cuantía de los derechos de importación de todos los bienes que no estuvieran produciéndose en el virreinato. Estos fueron los pormenores de su ponencia:

La propuesta medida de reducción de los derechos, solo debe tener lugar en los géneros de lencería extranjera (a excepción de los pintados, hilo de coser y encajes), en los de hierro, acero, clavezón, herramientas, instrumentos, máquinas, pertrechos marítimos y drogas medicinales; que convendrá mantener al actual sistema, en la mercería, loza y vidriería extranjera y el de la prohibición en los efectos de algodón y licor [...] y que respecto a las manufacturas de lana se deben recargar de nuevos derechos, para fomentar los nuestros y privar particularmente a los ingleses de sus ventajas. (Pombo, 2010, p. 124)

Más allá de las vicisitudes del comercio y el consumo, Pombo tuvo una mirada general de otros sectores de la economía virreinal. Le fue familiar el inconformismo y los sinsabores que continuaban despertando entre productores y consumidores la permanencia del monopolio estatal del tabaco y el aguardiente (rentas estancadas). No cabe duda que, para él, la solución definitiva pasaba por la liberalización de su producción y

Via Inveniendi Et Iudicandi

e-ISSN: 1909-0528 | DOI: https://doi.org/10.15332/19090528

Vol. 16 N.० 2 | julio-diciembre del 2021 
comercio; sin embargo, las autoridades coloniales aplazaron indefinidamente cualquier transformación y, posteriormente, serían las autoridades civiles republicanas del gobierno del general Tomás Cipriano de Mosquera las que finalmente tomarían cartas en el asunto y abolirían el estanco a finales de la década de 1840.

En este mismo tono liberal, José Ignacio de Pombo expuso su molestia por la conservación de la esclavitud como una de las formas de trabajo imperantes en el virreinato y el mundo. La opción más humana y racional era su abolición, por eso, paralelamente, siempre aconsejo a las autoridades españolas la promoción de la inmigración de mano de obra extranjera que pudiera aportarle conocimientos prácticos y técnicos a los nativos. Propuestas, que al igual que la anterior, entraron en saco roto, aplazándose su aplicación medio siglo, pues será con los gobiernos liberales de Tomás Cipriano de Mosquera y José Hilario López que se harían realidad, sabiendo que fueron pocos los inmigrantes extranjeros que acogieron la llamada de nuestros políticos y funcionarios públicos. Además, su programa de desarrollo incluyó el reforzamiento del perfil práctico y útil de la educación, que antes trataron de imprimirle algunos destacados personajes de la política virreinal (Torrejano, 2010b). Basta recordar, en este sentido, la propuesta impulsada por el fiscal Antonio Moreno y Escandón y el arzobispo virrey Antonio Caballero y Góngora en "dirección de la fundación de la universidad pública promotora de las ciencias útiles [...] en contribución al desarrollo de cocimientos prácticos [...] para caminar la senda del crecimiento económico" (Torrejano, 2010b, p. 64); hito de un despertar cultural presente en todos los virreinatos del imperio hispánico (Silva, 2004).

José Ignacio de Pombo insistirá en lo mismo: "escuelas de primeras letras y de agricultura: la erección en las ciudades principales de escuelas de dibujo, de estudios de mineralogía, de botánica, de química, de 
matemáticas, de medicina, y una universidad pública” (Pombo, 2010, p. 106).

El último aspecto de su programa consistió en auspiciar la navegación fluvial. Parte de sus obsesiones era unir, en el menor tiempo posible y a menor costo, la producción y el consumo. Frente a este y otros aspectos mejor leer sus apreciaciones con cierto lujo de detalle:

Facilitar la navegación de los ríos principales quitando e enmendando los estorbos que le impiden o le hacen peligrosa: la moderación de las leyes fiscales: la extinción de los estancos de aguardiente y tabacos [...] la del tributo de los indios, que los mantiene en su primitiva barbarie [...] el establecimiento de nuevas poblaciones o colonias rurales de unos y otros en parajes convenientes; la franquicia a los extranjeros católicos que quieran establecerse en ellas, o formar otras nuevas en el interior; la prohibición del comercio tan impolítico como bárbaro de negros, y un nuevo sistema para extinguir la esclavitud [...] el necesario limite a las adquisiciones de las manos muertas. (Pombo, 2010, p. 105)

Todas las proposiciones de los dos criollos son mucho más relevantes si no perdemos de vista que reflejan el generalizado malestar social y político imperante en la época, ese que explota a principios de la década del ochenta del siglo XVIII con el levantamiento de los comuneros, porque las 35 capitulaciones discutidas y preparadas, entre otros, por Juan Francisco Berbeo, Pedro Nieto, Pedro García, Javier Tello, Simón Villarreal y Jorge Lozano de Peralta, presentadas a las autoridades virreinales el 5 de junio de 1781, testimonian el disgusto por los impuestos y los obstáculos interpuestos al desarrollo de la economía; por eso pidieron la rebaja de los precios de la sal y el aguardiente, la extinción del tributo indígena, la abolición del derecho de Barlovento y el estanco del tabaco, del que se escribe en la sexta capitulación de la siguiente manera: 
$6^{\text {a }}$ Sexta. Que en el todo y por todo se haya de extinguir la renta frescamente impuesta del Estanco del Tabaco [...] el Excelentísimo Señor don Frey Pedro Messia de la Cerda, con el título de proyecto experimental, apartándose beneficio del público, fue la base en la que se cimentaron tamaños perjuicios como se han experimentado para los que le benefician, y con los canjes de otros frutos de este reino, lo trajinaban los pobres que alcanzaban a tener cinco cabalgaduras. (citado por Cárdenas, 1980, pp. 19-20)

Exigencias que no fueron de poca monta, puesto que afectaban las principales fuentes de ingresos fiscales de la corona española, según lo anota Jaramillo (1991): "los ingresos fiscales de mayor envergadura, que representaban cerca de la tercera parte del total (31.4\%), provenían de los estancos [...] del tabaco y el aguardiente" (p. 78).

\section{Programas para el desarrollo económico escritos a principios del siglo XIX: los casos de Camilo Torres Tenorio, Antonio de Villavicencio, Ignacio de Herrera y Vergara y Frutos Joaquín Gutiérrez}

Camilo Torres Tenorio, abogado payanés, le concedió un estrecho espacio al tema de las reformas económicas y sociales que urgía en el virreinato de la Nueva Granada, en el documento, Representación del Cabildo de Santafé, capital del Nuevo Reino de Granada, a la Suprema Junta Central de España o Memorial de Agravios, escrito en noviembre de 1809. En el documento subraya la nefasta gestión económica de la monarquía, porque no había sido propicia para promover el desarrollo y el bienestar de la población de las colonias. Por el contrario, la política colonial de España había dado como resultado el atraso y la pobreza en la que vivían sus habitantes. Camilo Torres planteó que la prosperidad en los territorios de ultramar vendría con la ejecución de una política económica basada en la liberalización del comercio, la abolición del estanco del 
tabaco, la eliminación del tributo indígena y el auspicio de la educación (Torres, 1960).

Por su parte, el criollo quiteño Antonio de Villavicencio, Comisario Regio, redactó en mayo de 1810 un pormenorizado informe al virrey Antonio Amar y Borbón sobre las causas del generalizado malestar e inconformismo de los criollos granadinos frente al gobierno español. Él dio cuenta de siete puntos. El primero fue que la administración pública estaba a cargo de funcionarios peninsulares sin pericia e ilustración. El segundo daba cuenta de una educación que descuidaba la formación en ciencias naturales y exactas. El tercero apuntaba a denunciar el abandono en el que se encontraban las comunicaciones terrestres y fluviales. El cuarto recriminaba a las autoridades por el excesivo peso de la carga fiscal, a la que se refería en términos de gravámenes penosos, como el diezmo, la alcabala, la sisa y el almojarifazgo. El quinto recordaba el despotismo con el que los funcionarios peninsulares trataban a los granadinos. El sexto la incompetencia de la justicia colonial y el séptimo insistía en la inconveniencia del tributo indígena (Villavicencio, 1960).

Si se efectúa el ejercicio de leer esta lista de quejas, en sentido propositivo, nos da la misma cantidad de puntos para componer un "hipotético" programa de gestión pública que tendría que desarrollarse, en opinión de Villavicencio, en uno de dos escenarios políticos probables: primero, en el de un ajuste del estatus colonial; segundo, en el de una la ruptura de los lazos de dominación colonial (Villavicencio, 1960). Sabiendo ya que la dinámica de los acontecimientos desembocaría en la Declaración de Independencia absoluta de España a partir del 11 de noviembre de 1811 (Cartagena de Indias), esos siete puntos se convirtieron en parte sustantiva de la agenda pública del gobierno republicano durante buena parte del siglo XIX.

Via Inveniendi Et Iudicandi

e-ISSN: 1909-0528 | DOI: https://doi.org/10.15332/19090528

Vol. 16 N.o 2 | julio-diciembre del 2021 
Entonces, a partir de la segunda década del siglo XIX, la carta de navegación de un Estado independiente y libre sigue la trayectoria de plasmar reformas adecuadas para la implementación de la educación útil y práctica; el patrocinio de inversiones conducentes al mejoramiento y la modernización de las comunicaciones y el transporte; la abolición de algunos impuestos que gravan el consumo y la producción; el establecimiento de un aparato de justicia eficiente; el desempeño aséptico e imparcial de cargos públicos; la aprobación de la libertad de cultivo y venta de tabaco y la supresión del tributo indígena (Villavicencio, 1960), que consideraba el impuesto más injusto e inicuo como leeremos a continuación:

Es el impuesto más injusto e inicuo que ha podido inventar la ignorancia y la malignidad para destruir esta utilísima, importantísima y desventurada casta de hombres, los más bien dispuestos por la naturaleza, no solo para el cultivo de las artes, pues su extraordinaria robustez y sobriedad y su natural comprensión, paciencia y moderación los hace a propósito para ella y dignos de mejor suerte [...] clama el cielo su justicia para que se les libre de tan bárbara opresión, se extinga el tributo que los envilece, entren ya en los derechos de todos los demás ciudadanos [...] y se les eleve a la clase de hombres libres. (Villavicencio, 1960, p. 117)

En lo que respecta al criollo Ignacio de Herrera y Vergara, el autor expuso en el ensayo, "Reflexiones que hace un americano imparcial al diputado de este Reino de Granada para que las tenga presente en su delicada misión”, elaborado en septiembre de 1809 y dirigido a don Antonio Narváez y la Torre para que las entregara a la Junta Central de España, sostuvo que el Virreinato de la Nueva Granada estaba irremediablemente postrado en un estado de barbarie desde la época de La Conquista, pues nunca se había 
promovido por parte de la monarquía una política que impulsara su desarrollo económico y avance cultural. Desde su punto de vista:

Las artes se hallaban en su infancia, no tenemos talleres, desconocemos las maquinas más necesarias y apenas logramos unos tejidos groseros que publican nuestra ignorancia [...] el trabajador camina sobre las huellas que dejaron sus mayores. En trescientos años no hemos adelantado nuestros conocimientos y parece que estos siglos únicamente han corrido para avergonzarnos con nuestra ignorancia. (Herrera, 1983, p. 510)

En su ensayo diagnosticó que la monarquía española sufría abulia, pues hizo muy poco o nada para auspiciar actividades disímiles a la explotación de metales preciosos, con lo que condenó a la Nueva Granada a depender de una economía extractiva rudimentaria y echó por la borda cualquier esfuerzo de auspiciar el sector productivo agrícola y manufacturero, a pesar de que "sus fecundas tierras se brindan al labrador, provocándole con abundantes frutos, tenemos el lino, los algodones y abundancia de lanas. El Reino vegetal es copioso en tintes, y nada nos falta" (Herrera, 1983, p. 518).

Igualmente, tampoco demostró algún interés por organizar la educación de los súbditos con base en sus requerimientos y necesidades profesionales, perfiladas desde la perspectiva de la explotación eficiente de los recursos naturales. En su opinión, la educación impartida durante los tres largos siglos de dominación nunca fue organizada atendiendo una orientación práctica y útil. Estos son renglones esclarecedores al respecto:

En los colegios de Indias se entretiene a la juventud muchísimos años, con el estudio de universales, con una física bárbara y con otras bagatelas que no traen utilidad. Hasta ahora no se ha puesto un maestro que nos enseñe Mineralogía: las minas se trabajan sin discernimiento y muchas veces se queda en las entrañas de la tierra los más preciosos porque se

Via Inveniendi Et Iudicandi

e-ISSN: 1909-0528 | DOI: https://doi.org/10.15332/19090528

Vol. 16 N.० 2 | julio-diciembre del 2021 
desconocen sus varias ramificaciones y distintas vetas. (Herrera, 1983, p. 519)

A su juicio, los dirigentes peninsulares nunca pusieron de su parte para promover la manufactura doméstica mediante una política proteccionista que la salvaguardara de la poderosa competencia inglesa y muchísimo menos pensaron la posibilidad de adelantar la inaplazable tarea de construir un mercado interno totalmente articulado, para lo cual creía que había que emprender un programa de construcción de caminos, dotados de hospedajes y brindándoles seguridad a los viajeros, dándole celeridad a las comunicaciones y disminuyendo los costos de transporte, con lo que saldrían ganando productores, mercaderes y consumidores, o por lo menos, haría más expedito el contacto entre producción y consumo. Pero dejemos que sea el propio Herrera y Vergara el que nos los describa:

La capital del Nuevo Reyno de Granada tiene provincias fértiles, abundantes en frutos, y no los logra. La de Popayán produce algodones finos, que sembrados una vez no hay necesidad de nuevos plantíos como acontece en el Socorro. Allí se encuentra el café, la quina y el cacao. Sus moradores se contentan con la siembra de lo que entre ellos se consume. Hacia el lado de la capital se les opone la montaña del Quindío que les impide la exportación. Mientras no se faciliten los caminos no se puede progresar el comercio. A esto se le ha de añadir el establecimiento de hospederías para los conductores y abundancia de forrajes y seguridad en las cabalgaduras. Por el desatino o abandono de nuestros caminos tenemos poblaciones enteras que nunca han venido a la capital. ¿Y cómo conducirían a ella sus frutos? ¿Con qué fuerzas los llevarían a otros lugares? los costos de la exportación, la pérdida de sus bestias, las fatigas y el ningún asilo a donde puedan acogerse, los precisa a mantenerse en la inacción. (Herrera, 1983, p. 520)

Así mismo, criticó la permanencia del tributo indígena. Era preferible dejarlos en completa libertad e incluirlos en los avatares del juego del 
mercado libre, la igualdad civil y la visibilidad fiscal, para que participaran de las mismas obligaciones jurídicas y tributarias del resto de habitantes del virreinato. "Mejor es dejarlos libres, que paguen las alcabalas y demás impuestos del Estado. Entonces desenvolverán sus talentos, trabajarán con más utilidad en la labor de las tierras, pondrán talleres y se destinarán a las artes útiles" (Herrera, 1983, p. 523).

Finalmente, amparado en la misma perspectiva de jugarse el todo por el todo en la rápida introducción de ajustes estructurales liberales en el escenario económico, fue uno más de los criollos que le apuntaron a la abolición de las rentas estancadas del tabaco y el aguardiente, porque "son un mal imponderable como lo han demostrado los economistas; no solo para la agricultura del Reyno y su población, sino para la metrópoli, su navegación, y aun para el mismo erario" (Herrera, 1983, p. 525).

Por su parte, el criollo Frutos Joaquín Gutiérrez plasmó en el documento "Motivos que han obligado al Nuevo Reino de Granada a reasumir los derechos de la soberanía, remover las autoridades del antiguo gobierno e instalar una Suprema Junta bajo la sola denominación y en nombre de nuestro soberano Fernando VII y con independencia del Consejo de Regencia y de cualquiera otra representación”, redactado a finales de septiembre de 1810, continuó la línea trazada por los criollos ilustrados desde finales del siglo XVIII, insistiendo en las mismas factores causantes del estado de atraso y pobreza del virreinato, sobre todo hizo fuerza en destacar que el objetivo macroeconómico de la monarquía española en América había sido impedir a toda costa su desarrollo. Él lo expresó con estas palabras:

Bastaba nombrar a la América, para saber que se hablaba de un país inmenso en donde el Gobierno no permitía las ciencias, ni las artes, ni la agricultura, ni el comercio; en donde eran delito las escuelas, las fábricas, la industria y el trabajo. (Gutiérrez, 1960, p. 211)

Via Inveniendi Et Iudicandi

e-ISSN: 1909-0528 | DOI: https://doi.org/10.15332/19090528

Vol. 16 N.० 2 | julio-diciembre del 2021 
También recalcó el deplorable estado en el que permanecían los indígenas como consecuencia del tributo indígena. Estas fueron sus palabras al respecto:

La felicidad pública se quejaba también de ver a los indios bajo el yugo de un injusto y tiránico tributo. Después de exigirles todo el precio de sus labores, se les abandonaba como a bestias; no había en su pueblo una escuela pública para educarlos, ni un hospital para curar sus enfermedades, pero ni tenían cama en que dormir, ni pan que comer, pereciendo las tres partes de ellos de necesidad y miseria. (Gutiérrez, 1960, p. 211)

Finiquitando sus disquisiciones con la denuncia de varios casos en los que las autoridades españolas frustraron el avance de algunas prometedoras iniciativas empresariales. Él nunca dudaría que la única fórmula para darle vía libre a la iniciativa privada doméstica era independizándose de España como se deduce a continuación:

¿Pero qué diremos de los perjuicios que las artes y la agricultura han recibido de este fatal gobierno? Nada se permitía hacer a los americanos. El D. Lazo plantó el lino en Bogotá, el gobierno reprobó aquel plantío. El doctor Neira puso algunas cepas en Sutatenza, el gobierno las arrancó [...] En Santafé puso D. Juan de Illanes un batán, el gobierno lo perdió. Chavarría intentó fabricar losa para el servicio de mesa, el gobierno se lo impidió [...] Pierri estableció fábrica de sombreros, el gobierno puso mil trabas a su proyecto. (Gutiérrez, 1960, p. 211)

Para el sacerdote Eloy Valenzuela, el programa ideal de desarrollo económico empezaba con la imperiosa necesidad de incentivar la migración de mano de obra calificada y empresarios extranjeros que profesaran el credo católico, luego debería aprobarse una reforma del sistema fiscal imperial, seguido por la ejecución de un ambicioso proyecto 
de construcción de infraestructura vial y rematar con una fuerte inversión en educación básica. Miremos toda esta proposición con más detalle:

El avecindamiento y buena acogida de cuantos extranjeros traigan alguna industria o vengan a entablar ingenios, desmontar tierras o labrar minas [...] con tal que se [...] conformen con la religión del país [...] tienen influjo directo sobre la prosperidad del Reyno: el sistema de contribuciones poco tiene que variar pero su cobro es complicado, costoso y sujeto a mucho fraude [...] la creación de escuelas en todas las parroquias [...] del mismo modo se podrán habilitar los caminos largos y costosos, añadiendo la merced de algunas tierras y la recompensa de un moderado pecho sobre las cargas. (Valenzuela, 2008, p. 185)

\section{Programa para el desarrollo económico refrendado a principios del siglo XIX: diligencia de la naciente clase dirigente}

En el fondo, todas las anteriores propuestas programáticas poseen el común denominador de apuntar hacia la liberalización de la economía. La consigna fue destruyamos el mercantilismo (Mosquera y González, 2020). La independencia sería la oportunidad de poner en práctica todas estas iniciativas de progreso. En dicho menester, los criollos pusieron manos a la obra. Lo primero que puede apreciarse es la diligencia de la naciente clase dirigente regional y nacional en algunas actas de declaración de independencia redactadas entre 1810 y 1813 ; en ella fijaron su propio réspice polum en procura del desarrollo económico.

Por ejemplo, en el Acta del Cabildo Extraordinario, realizado el 30 de junio de 1810 en San Juan de Girón, para depositar el gobierno local en el doctor Eloy Valenzuela, cura de la parroquia de Bucaramanga, consta que este personaje histórico puso a los demás miembros de la Junta a jurar el respaldo de su programa de desarrollo local, que contenía básicamente estos acápites: trabajar por el bienestar de los cosecheros del tabaco y 
adelantar reforma fiscal suprimiendo algunos tributos y gravando el consumo suntuario (Acta del cabildo extraordinario de Girón, 2008).

Paralelamente, la Junta Provincial de Antioquia, integrada, entre otros personajes, por Francisco Ayala, presidente, Elías López, vicepresidente y vocales Manuel Martínez, Joaquín Gómez, José Miguel de la Calle e Isidoro Peláez, fijó programa de avance económico fundamentado en la extinción del estanco del tabaco y el aguardiente, la muerte de un tributo cancelado por los mineros artesanales o mazamorreros y la abolición de la alcabala. Observemos esta determinación de la Junta:

Se acuerda en beneficio de estos pueblos y en fomento de la agricultura e industria, que los expresados ramos de aguardiente y tabaco queden y sean en lo sucesivo de libre comercio, pudiéndose cosechar, destilar y consumir dentro de la provincia [...] A los mazamorreros, o lavadores de oro, no se les exigiría el derecho llamado de mazamorras por ser perjudicial al erario y a la industria [...] juzgándose corruptela el dos y cuarto por ciento de alcabala que se cobra al comercio en esta provincia, cuando en todas las demás, solo se satisface un dos conforme a la ley, se declara abusivo el exceso de los dos reales, que en lo venidero no se cobrarán ni se pagarán. (Noticia de la Junta Provincial de Antioquia, 2008, pp. 218-219)

A la par, los criollos firmantes de la Declaración de Independencia Absoluta de la Provincia de Tunja en diciembre de 1813, también pusieron los puntos sobre las íes en el común denominador de los programas de progreso económico, destacándose la parte aquella en la que se pide trabajar por el montaje de una educación moderna, científica y útil, toda vez que el gobierno monárquico español siempre aplicó "instrucciones expresas para no consentir, entre nosotros, la propagación de los conocimientos humanos" (Declaración de Independencia de la Provincia 
de Tunja, 2008, p. 297) y el desmonte inmediato del sistema de monopolio comercial como apreciamos a continuación:

El comercio sujeto a un canal estrecho por donde se cambiaban a vil precio los frutos coloniales contra los europeos, que se vendían por tres o cuatro tanto más de lo que hubieran valido en un mercado libre. Esa usura pública y nacional aumentaba las corrientes de nuestro numerario, que de las manos de los mineros pasaba a la de los monopolistas, sin que sirviese a los adelantamientos del país que lo producía. (Declaración de Independencia de la Provincia de Tunja, 2008, p. 297)

El segundo capítulo de la política de liberalización económica de la República, se escribió entre las décadas del cuarenta y el setenta del siglo XIX. Durante este periodo encontramos gobiernos liberales que empujaron un conjunto de reformas que trajeron consigo la extinción del estanco del tabaco, la disolución de resguardos, la abolición de la esclavitud, la rescisión del tributo indígena, el fomento de la navegación a vapor por el río Magdalena, y la promoción de la inmigración extranjera (Melo, 1991; Melo, 2017; Meisel, 2010; Ocampo, 1998; Ocampo, 2010; De la Pedraja, 1979; Zambrano, 1979; Kalmanovitz, 2010; Kalmanovitz; 1997; Palacios y Safford, 2012; Safford, 2010; Tovar, 2010; Tirado, 1988). Todas estas reformas al sistema económico liberaron los factores de producción (capital, tierra y trabajo) y contribuyeron a "aumentar la movilidad de la mano de obra [...] la movilidad de tierras [...] y la movilidad de capital, con el desarrollo del sistema de crédito y la aparición de los bancos comerciales" (Meisel, 2010, p. 12).

Sin embargo, la década anterior, al inicio del ciclo de reformas económicas de la mitad del siglo XIX, los gobernantes neogranadinos encargados de la dirección del nuevo Estado dudaron de las ventajas del sistema económico liberal. Para los presidentes Francisco de Paula Santander y José Ignacio de Márquez (quien desempeño el cargo de ministro de Hacienda del 
gobierno de Domingo Caicedo), y de manera especial para el ministro de Hacienda del primero de ellos, Francisco Soto, el camino del progreso económico pasaba por los predios del proteccionismo. En su concepto los bienes extranjeros compatibles con los producidos en Colombia debían gravarse con una tasa más alta que la que soportaban las mercancías que carecían de equivalencia entre nosotros, porque la producción doméstica todavía era incapaz de competir con la producción foránea y todo esto inexorablemente conduciría a la ruina de cualquier iniciativa empresarial. La posición proteccionista del ministro quedó perfectamente definida en la memoria que presentó al Congreso en 1830, como se lee a continuación:

Necesario es que aquellos efectos extranjeros que son análogos a los de la producción interior, paguen un impuesto mucho más crecido que aquellos que no tienen su equivalente entre nosotros. De otro modo habrá de consultar, como alguna vez ha sucedido, que nuestros artefactos nacientes no puedan concurrir con los del extranjero, y caigan por lo mismo en el estado de languidez, que insensiblemente los conduzca a su aniquilamiento. El Poder Ejecutivo [...] cree que la libertad de comercio exterior no debe envolver nunca la ruina de las manufacturas interiores. (citado por Galindo, 1978, p. 121)

La posición antiliberal también se plasmó en la memoria de hacienda que presentó José Ignacio de Márquez al Congreso en 1831, indicando que el atraso de la manufactura y la producción agrícola criolla primordialmente se debía a la competencia proveniente del exterior, por lo que se necesitaba ponerle trabas a la importación de ciertas mercancías, hasta el punto de prohibir el ingreso al mercado interno de varias de ellas, según se observa en el siguiente párrafo de dicha memoria:

Las artes [...] están bien atrasadas entre nosotros [...] Este mal proviene principalmente de la extensión ilimitada que se ha dado al comercio extranjero [...] si se quiere, pues, vivificar el comercio interior y

Via Inveniendi Et Iudicandi

e-ISSN: 1909-0528 | DOI: https://doi.org/10.15332/19090528

Vol. 16 N.० 2 | julio-diciembre del 2021 
beneficiar a los colombianos, preciso es que se pongan trabas al comercio extranjero, prohibiendo absolutamente la introducción de varios géneros, frutas y efectos que se producen en nuestro país, y de todo cuanto puedan proporcionarnos nuestras nacientes artes [...] limitada la libertad de comercio se aumentará infaliblemente el consumo de nuestras manufacturas, crecerán las demandas, se multiplicará la producción, se mejorarán nuestras fábricas, se cultivarán las materias primas, y quedarán entre nosotros los valores producidos y el valor de la moneda. (citado por Galindo, 1978, p. 121)

Esta tendencia proteccionista dejó su huella en el ajuste de la estructura fiscal, en especial, la eliminación de impuestos a las exportaciones pasándoselos a las importaciones. Con detalle este arreglo fiscal lo explica Meisel (2010):

En las primeras décadas de vida independiente las autoridades económicas de la Nueva Granada lograron reformar y mejorar de manera gradual, pero significativa, el sistema fiscal heredado de España [...] El principal cambio en esta materia fue que se eliminaron los impuestos a las exportaciones y se concentró el sistema fiscal en los impuestos a las importaciones [...] A mediados del siglo XIX el grueso del sistema fiscal recaía en estos impuestos sobre las importaciones. (p. 11)

Para mediados de la década de 1840, se daría por terminado el tiempo asignado a la protección económica y se abrirían las puertas para la aplicación del vademécum liberal esbozado desde finales del siglo XVIII, con la fuerza del argumento que el proteccionismo lejos de traerle al país progreso y bienestar, había obstaculizado, e incluso detenido, el avance de la manufactura y la creación de riqueza, según lo expuso Aníbal Galindo en escrito redactado como Jefe de la Oficina de Estadística Nacional en 1874, como consta a continuación: 
Las ideas económicas de los más adelantados estadistas neogranadinos de esa época, no son pues, sino el reflejo, y casi pudiera decirse, una copia servil de las doctrinas de Ganilh y de los demás oráculos del proteccionismo europeo [...] deducida de la rigurosa observación de los hechos, de que esas doctrinas lejos de estimular el trabajo nacional, de alimentar la riqueza pública y de mejorar la condición fiscal del Estado, no hacen sino retardar los progresos de la industria, hacerla languidecer en el sopor del privilegio y mantener estancado el desenvolvimiento de la riqueza y de los recursos fiscales de la nación [...] los 26 años que duró en ejercicio el sistema protector, que restringía con altísimos derechos la importación de los tejidos de algodón [...] y el calzado, los muebles, la ropa, las sillas de montar, la cerveza, el hierro, el cobre en bruto, la harina, la pólvora, el sebo manufacturado, la loza y otros artículos de producción nacional, no dejaron la menor huella de progreso o adelanto en la industria fabril del país. (Galindo, 1978, pp. 120-124)

Para Aníbal Galindo, el motor del desarrollo económico y la creación de riqueza estaba compuesto de dos piezas: libertad y competencia. Esta última era el perfecto incentivo para cualificar la rústica mano de obra existente en la nación. Desde su punto de vista, “el país no ha tenido artesanos de primera clase [...] que rivalicen con los productos extranjeros, sino cuando en medio de la libertad, el estímulo de la competencia los ha obligado a formarse” (Galindo, 1978, p. 124), sin olvidar la formación práctica en la escuela y la introducción de máquinas modernas en la producción (Camacho, 1923). Para finalizar, pensando que la continuidad del sistema proteccionista habría ocasionado el retorno del país al feudalismo (Galindo, 1978). Temor de retroceso que colisionó con la gran expectativa liberal de cambio que venía envolviendo a los dirigentes políticos nacionales, fruto de la vertiginosa serie de acontecimientos revolucionarios que estaban desencadenándose en Europa occidental y que Salvador Camacho Roldán (1923) registró en sus memorias: 
La reforma electoral en Inglaterra, en 1830, y el triunfo de la Liga de los cereales, en 1846, medidas que constituyen una gran brecha en los privilegios de la aristocracia de sangre; el establecimiento de un régimen parlamentario en España en reemplazo del corrompido gobierno absoluto asumido por Fernando VII desde 1814 hasta 1833 y la desamortización de bienes de manos muertas realizada en 1837; la caída de la rama mayor de los Borbones en Francia, en 1830, y de la rama de Orleans en 1848, seguida por la proclamación de la república. (p. 52)

\section{Conclusión}

Las iniciativas de reforma económica presentadas por ilustrados y connotados criollos desde finales del siglo XVIII, en el marco de la dominación imperial española, apuntaron hacia la profundización y la celeridad de los ajustes estructurales de orden liberal que venían perfilándose desde la península ibérica con el espíritu reformista borbónico de Carlos III. Enfatizaron la pronta liberalización del comercio, la producción y la fuerza de trabajo, con medidas tales como la abolición de varios impuestos que grababan la circulación, la extinción de algunas retas estancadas (particularmente tabaco y aguardiente), la abolición del tributo indígena y la manumisión de esclavos negros. Todo esto acompañado de una estrategia de fomento de la construcción de una adecuada infraestructura de comunicaciones y transporte que facilitara el contacto intra e interregional para llevar sus bienes al mercado regional y externo. Planes que dejaron de concretarse durante el corto tiempo de vida que le quedaba al imperio español en suelo neogranadino, aplazándose su ejecución (nada exenta de contradicciones) para la primera mitad del siglo XIX, sobre todo a partir del primer gobierno de Tomás Cipriano de Mosquera (1845-1849). 


\section{Referencias}

Acta del Cabildo extraordinario realizado el 30 de julio de 1810 en San Juan de Girón para depositar el gobierno local en el doctor Eloy Valenzuela (2008). En I. Quintero y A. Martínez (eds.), Actas de formación de junta y declaraciones de independencia 1809-1822 (pp. 186-189). Universidad Industrial de Santander.

Camacho, S. (1923). Memorias de Salvador Camacho Roldan. Bedout.

Declaración de Independencia de la Provincia de Tunja el 10 de diciembre de 1813 (2008). En I. Quintero y A. Martínez (eds.), Actas de formación de junta y declaraciones de independencia 1809-1822 (pp. 296-300). Universidad Industrial de Santander.

De la Pedraja, R. (1979). Los cosecheros de Ambalema: un esbozo preliminar. Anuario Colombiano de Historia Social y de la Cultura, (9), 39-63. https://revistas.unal.edu.co/index.php/achsc/article/view/36241

Galindo, A. (1978). Estudios económicos y fiscales. Colcultura.

Gutiérrez, F. (1960). Motivos que han obligado al Nuevo Reino de Granada a reasumir los derechos de la soberanía, remover a las autoridades del antiguo gobierno e instalar una Suprema Junta bajo la sola denominación y en nombre de nuestro soberano Fernando VII y con independencia del Consejo de Regencia y de cualquiera otra representación. En Proceso histórico del 20 de julio de 1810 documentos (pp. 210-249). Banco de la República de Colombia.

Herrera, I. (1983), Reflexiones de un americano imparcial sobre la legislación de las colonias españolas 1809. En J. Ocampo, El proceso ideológico de la emancipación en Colombia (pp. 509-529). Tercer Mundo.

Kalmanovitz, S. (1997). Economía y nación: una breve historia de Colombia. Tercer Mundo.

Kalmanovitz, S. (2008). Consecuencias económicas del proceso de independencia en Colombia. Universidad Jorge Tadeo Lozano.

Kalmanovitz, S. (2010). Nueva historia económica de Colombia. Universidad Jorge Tadeo Lozano.

Jaramillo, J. (1991). La economía del virreinato 1740-1810. En J. Ocampo (ed.), Historia económica de Colombia (pp. 49-83). Siglo XXI.

Via Inveniendi Et Iudicandi

e-ISSN: 1909-0528 | DOI: https://doi.org/10.15332/19090528

Vol. 16 N.० 2 | julio-diciembre del 2021 
Llano, J. V., Rengifo, R. y Rojas, L. (2018). Estado cosmopolita en América Latina. Revista IUSTA, (48), 97-117. https://doi.org/10.15332/s1900-0448.2018.0048.04

Lynch, J. (1987). Hispanoamérica 1750-1850, ensayos sobre la sociedad y el Estado. Universidad Nacional de Colombia.

Martínez, T. (1994). Algunas reflexiones sobre el comercio colonial. Cuadernos de Estudios Empresariales, (4), 193-233. https://dialnet.unirioja.es/servlet/articulo? $\operatorname{codigo}=164207$

Melo, J. (1991). Las vicisitudes del modelo liberal 1850-1899. En J. Ocampo (ed.), Historia económica de Colombia (pp. 115-171). Siglo XXI y Fedesarrollo.

Melo, J. (2017). Historia mínima de Colombia. Turner Publicaciones y Colegio de México.

Meisel, A. (2010). ¿Qué ganó y qué perdió la economía de la Nueva Granada con la independencia? Cuadernos de historia económica y empresarial, (27), 1-17.

Mosquera, L. y González, A. (2020). Las brechas socioeconómicas y su relación con la corrupción: elementos clave a la hora de formular políticas públicas. Revista IUSTA, (52), 103-122. https://doi.org/10.15332/25005286.54850 hixi

Naranjo, C., Naranjo, A. y Navas, C. (2018). Sobre el discurso alrededor de las ideas de revolución en América Latina. Revista IUSTA, 2(49), 169-192.

https://doi.org/10.15332/s1900-0448.2018.0049.07

Narváez, A. (2010). Provincia de Santa Marta y Riohacha del Virreinato de Santafé 1778. Banco de la República de Colombia.

Noticia de la Junta Provincial de Antioquia del 22 de septiembre de 1810 (2008). En I. Quintero y A. Martínez (eds.), Actas de formación de junta y declaraciones de independencia 1809-1822 (pp. 186-189). Universidad Industrial de Santander.

Ocampo, J. A. (1998). Colombia y la economía mundial 1830-1910. Tercer Mundo, Fedesarrollo y Colciencias.

Ocampo, J. A. (2010). El sector externo de la economía colombiana en el siglo XIX. En A. Meisel y M. Ramírez (ed.), Economía colombiana el siglo XIX (pp. 201-240). Fondo de Cultura Económica.

Palacios, M. y Safford, F. (2012). Historia de Colombia, país fragmentado, sociedad dividida. Universidad de los Andes.

Via Inveniendi Et Iudicandi

e-ISSN: 1909-0528 | DOI: https://doi.org/10.15332/19090528

Vol. 16 N.० 2 | julio-diciembre del 2021 
Plan de capitulaciones (1980). En P. Cárdenas. El movimiento comunal de 1781 en el Nuevo Reino de Granada T. II (pp. 18-29). Tercer Mundo.

Pombo, J. (2010). Memoria sobre el contrabando en el virreinato de Santafé. Banco de la República de Colombia.

Stanley, J. y Stein, B. (1981). La herencia colonial de América Latina. Siglo XXI.

Safford, F. (2010). El problema de los transportes en Colombia. En A. Meisel y M. Ramírez (ed.), Economía colombiana del siglo XIX (pp. 523-570). Fondo de Cultura Económica.

Silva, R. (2004). Prensa y revolución a finales del siglo XVIII. La Carreta.

Torrejano, R. (2010a). Las reformas económicas y políticas borbónicas: certeza e incertidumbre en una época convulsionada. Revista Republicana (8), 93-108.

Torrejano, R. (2010b). La educación a finales del periodo colonial 1787-1806: entre lo útil y lo inútil. Revista Universidad EAFIT, 46(158), 64-81.

Tirado, A. (1988). Introducción a la historia económica de Colombia. El Áncora Editores.

Torres, C. (1960). Representación del Cabildo de Santafé, capital del Nuevo Reyno de Granada, a la Suprema Junta Central de España 1809. En Proceso histórico del 20 de julio de 1810 documentos (pp. 85-109). Banco de la República de Colombia.

Tovar, J. (2010). La manumisión en Colombia 1821-1851. En A. Meisel y M. Ramírez (eds.), Economía colombiana del siglo XIX (pp. 483-520). Fondo de Cultura Económica.

Valenzuela, E. (2008). Carta del doctor Eloy Valenzuela a don José Fernández Madrid. En I. Quintero y A. Martínez (eds.), Actas de formación de junta y declaraciones de independencia 1809-1822 (pp. 186-189). Universidad Industrial de Santander.

Villavicencio, A. (1960). Representación del comisario regio don Antonio de Villavicencio al Virrey de Santafé. En Proceso histórico del 20 de julio de 1810 documentos (pp. 85-109). Banco de la República de Colombia.

Zambrano, F. (1979). La navegación a vapor por el río Magdalena. Anuario Colombiano de Historia Social y de la Cultura, (9), 63-77.

Via Inveniendi Et Iudicandi

e-ISSN: 1909-0528 | DOI: https://doi.org/10.15332/19090528

Vol. 16 N.० 2 | julio-diciembre del 2021 